\title{
نظرية المعرفة عند الفيلسوف محمد إقبال
}

\section{Epistemology by the philosopher Muhammad Iqbal}

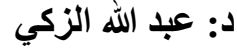 \\ أستاذ زائر بجامعة شعيب الدكالي بالجديدة، المغرب
}

Dr. Abdullah EZZAKY, visiting professor at Shoaib Al-Doukkali University in El Jadida, Morocco

Email : zakymary@gmail.com

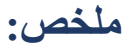

هذه الدر اسة هي محاولة للوقوف على رؤية الفيلسوف الدكتور محمد إقبال اللاهوري فيما يتعلق بنظرية المعرفة، ومقارنتها مع رؤية فلاسفة اليونان كسقراط و أفلاطون و أرسطو، وكذللك فلاسفة الإسلام و المتكلمون لهوني و المتصوفة، وذللك من خلال الإجابة على الأسئلة التالية:

كيف كانت نظرة فلاسفة اليونان لنظرية المعرفة؟ وكذلك المسلمون فلاسفة ومتكلمين ومنصوفة؟؟ وما هي

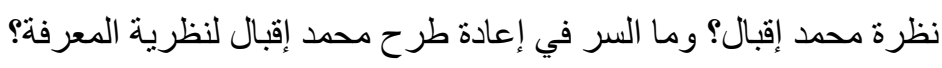
الكلمات المفتاحية: إقبال، الفيلسوف، نظرية، المعرفة، الابستمولوجيا. 


\section{Epistemology by the philosopher Muhammad Iqbal}

\section{Abstract:}

This study is an attempt to discover the vision of the philosopher, Dr. Muhammad Iqbal Al-Lahuri with regard to epistemology, and to compare it with the vision of Greek philosophers such as Socrates, Plato and Aristotle, as well as philosophers of the, theologians and Sufis. And it is by answering the following questions:

How did Greek philosophers view the theory of knowledge? As well as Muslims, philosophers, theologians and Sufis?

What is the opinion of Muhammad Iqbal ? What is the secret of Muhammad Iqbal's reintroduction of the theory of knowledge.?

Keywords: Iqbal ; philosopher ; theory ; knowledge ; epistemology ;

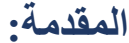

$$
\begin{aligned}
& \text { يهتم مبحث المعرفة أو ما يعرف بمبحث الإبستمولوجيا بدر اسة المعرفة الإنسانية بصفة عامة وحدودها } \\
& \text { و العلم من حيث شروط الصواب و الخطأ فيه أو الطرق المؤدية إلى اكتساب المعرفة. } \\
& \text { ونظرية المعرفة قديمة قدم الزمان عالجها فلاسفة اليونان من أمثال سقر اط و أفلاطون وتلميذه أرسطو ... } \\
& \text { وتعرض لها المسلمون بالدرس وبرز الاهتمام بها في العصور الحديثة، فكانت في مقدة المسائل الفلسفية } \\
& \text { المطروحة. فكيف كانت نظرة فلاسفة اليونان لنظرية المعرفة؟ وكذلك المسلمون فلاسفة ومتكلمين ومتصوفة؟؟ وما } \\
& \text { هي نظرة محمد إقبال؟ وما السر في إعادة طرح محمد إقبال لنظرية المعرفة؟ } \\
& \text { هذه الأسئلة هي التي يحاول هذا البحث مقربتها من خلال المحاور التالية: } \\
& \text { مقدمة: } \\
& \text { المطلب الأول: المعرفة عند اليونان: المعان } \\
& \text { المطلب الثاني: المعرفة عند فلاسفة الإسلام: } \\
& \text { المطلب الثالث: المعرفة عند المتكلمين: } \\
& \text { المطلب الر ابع: المعرفة عند فلاسفة الغرب المحدثين: } \\
& \text { المطلب الخامس: المعرفة عند إقبال : } \\
& \text { خاتمة: }
\end{aligned}
$$




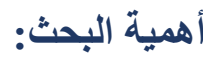

تعتبر نظرية المعرفة أساس وركيزة ضرورية ترتكز عليها أي فلسفة علمية حيث أن بناء النظرية المعرفية حجر أساس تقوم عليه فلسفة العلوم. ويتجلى الفارق الحقيقي بين الفلسفات المختلفة ، في مرتكز ات ومصنادر نظرية

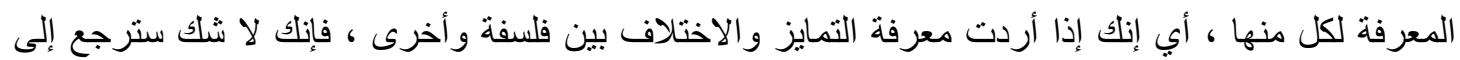
المصادر والمرتكز ات والأسس النظرية المعرفية لتلك الفلسفات ـ من هذا المنطلق يستمد هذا البحث أهميته لأنه يحاول البحث في أوجه الاختلاف والاتفاق بين رؤية بعض فلاسفة اليونان و الفلاسفة الإسلاميين و علماء الكلام، ورؤية الفيلسوف محمد إقبال اللاهوري.

\section{أهداف البحث}

\section{ل ح تبيان رؤية فلاسفة اليونان لنظرية المعرفة}

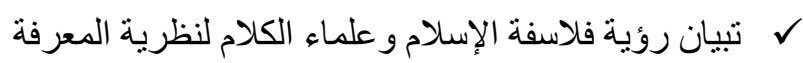
ل مقارنة بين الرؤيتين ل كبيان رؤية محمد إقبال لنظرية المعرفة و أهم ما تميزت به رؤينه

\section{المطلب الأول: المعرفة عند اليونان:}

أولى فلاسفة اليونان عناية كبيرة لمبحث المعرفة فاعتبر ها أفلاطون تذكر ا تحمله النفس من عالم المثل (')،

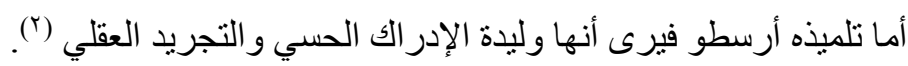
وقد اهتم الرو اقيون بمبحث إلى المعرفة فذهبوا إلى أنها تعتمد على الحس مباشرة وصادرة عنه، وأن المعيار الصحيح فيها هو دائما الأخلاق و العمل (־).

وذهب الأبيقوريون إلى أنه من دون المعرفة أيا كانت درجتها من اليقين لا يمكن للإنسان أن يعمل فلكي

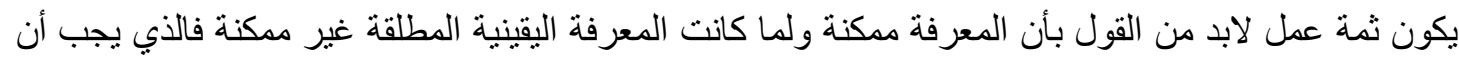
يقال حينئذ هو أن المعرفة ممكنة هي المعرفة الظنية (؛). و هكذا يتضح لنا أن أفلاطون و أرسطو و الرواقيون و الأبيقوريون يؤمنون بإمكان قيام معرفة بشرية. ونجد

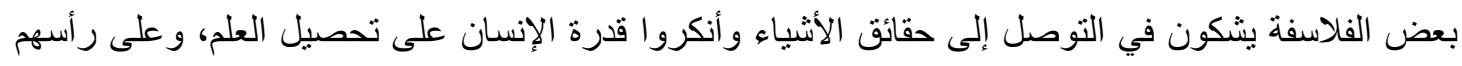

(1) د عثمان أمين: دراسات فلسفية مهداة إلى الدكتور إبراهيم مذكور: الهيئة المصرية العامة للكتاب: القاهرة ع 9 ا م

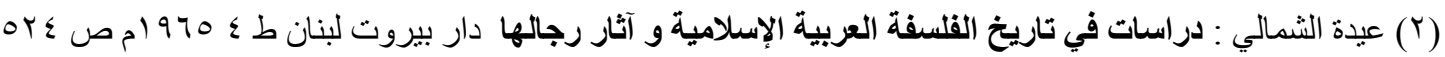

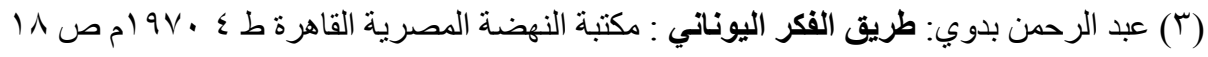




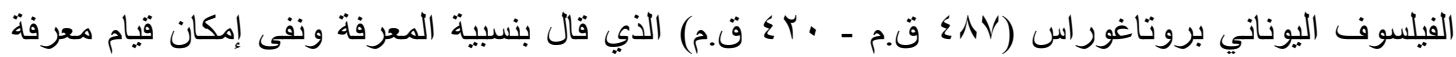

$$
\text { ويمكننا تقسيم آر اء فلاسفة اليونان حول نظرية المعرفة إلى قسمين: }
$$

الاعتقاديون الذين برون إمكان قيام عرفان بشري و أنه ليس للمعرفة الإنسانية نهاية تقف عندها حتى و إن

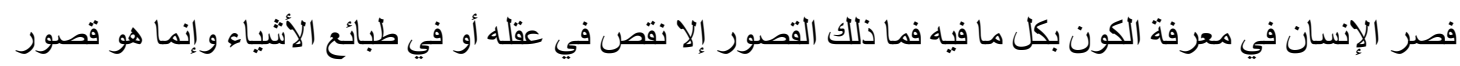
مر هون بزو ال العو ائق، و هذا الر أي أرسى قو اعده سقر اطو وتلاميذه من بعده (r). الثكاك الذين يرون أنه ليس للجهل الإنساني بحقائق الأشياء حد يقف عنده إذ لا وسيلة أمام الإنسان في

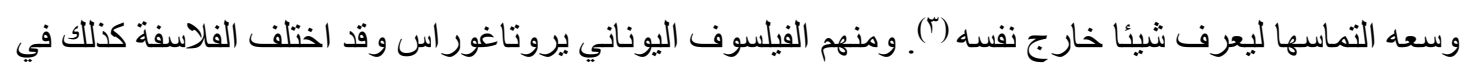

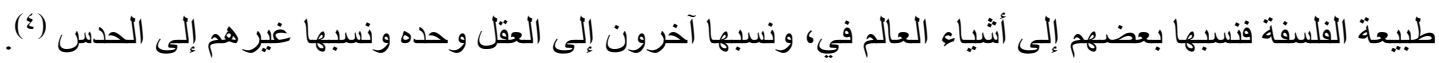
وقد اختلفوا في مصادر ها فقال بعضهم بالخبرة الحسية والحواس وعرف هؤلاء بالحسين أو التجريبيين و قال غير هم بالإدر الك المباشر و العقل و هؤ لاء هم العقليون وجمع فريق بين الحواس و العقل، و أخضع كل معرفة

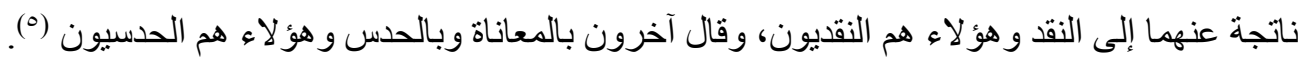

\section{المطلب الثانى: المعرفة عند فلاسفة الإسلام:}

اهتم فلاسفة الإسلام اهتماما ملحوظا بمصادر المعرفة وطبيعتها وذللك استنادا إلى نضر الإسلام الذي يعترف

بكل مصادر أو وسيلة مؤدية إلى تحقيق المعرفة أو العلم بأي أمر من أمور العقيدة والدين و الحياة ( 7). فقد اعتبر الكندي أن الحس هو أحد المصادر الأساسية للمعرفة "وهو مشترك بين الإنسان والحيوان ولا مؤنة فيه ولا صعوبة، و هو يدرك المحسوسات المادية الجزئية الدائمة التغير، التي لها صورة في المخيلة، و التي لهي

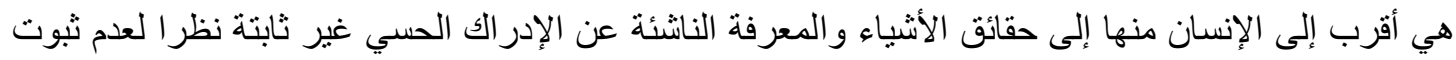

$$
\text { موضو عها من حيث الكيف"(V). (v). }
$$

كما اعتبر العقل المصدر الثاني للمعرفة حيث عرفه بقوله" العقل جو هر بسيط مدرك للأشياء بحقائقها"(^).

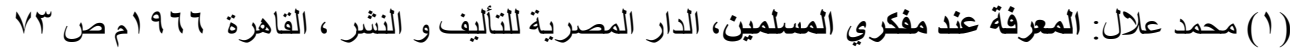

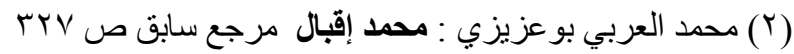

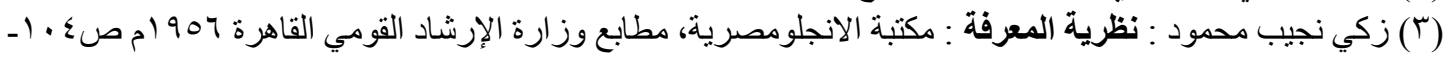


و أضاف الكندي مصدر اثالثا للمعرفة هو الوحي و الإلهام وهذا يختص به الأنبياء وحدهم وأطلق على هذه

المعرفة، المعرفة الإلهية أو العلم الإلهي ( (1)، وهو هنا يكون قد احتفظ بثو ابت العقيدة الإسلامية (؟).

أما الفار ابي فيؤكد في نظرية المعرفة على دور الحس وما له من أهمية إذ يقول "إن المعارف إنما تحصل

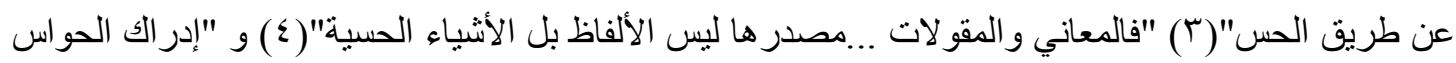

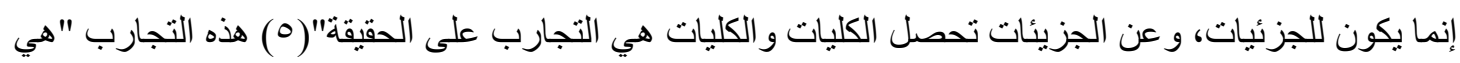

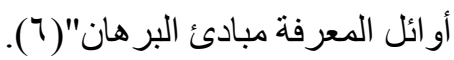

أما الوسيلة الثانية لتحصيل المعرفة عند الفار ابي فهي العقل ، حيث اهتم بها اهتماما كبير ا ، فوضع رسالة سماها "رسالة العقل" استعرض فيها ستة أنو اع من العقول ، و هي العقل بالقوة أو الهيو لاني و العقل بالفعل و العقل

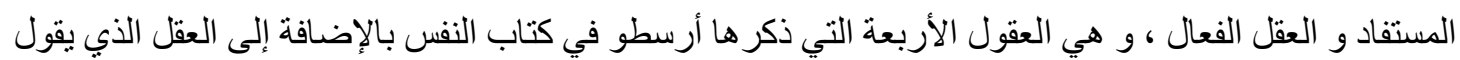

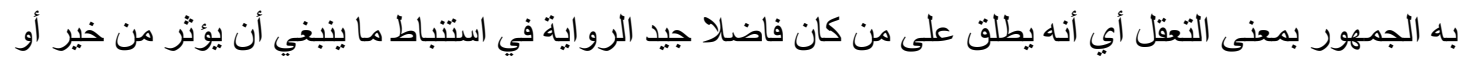

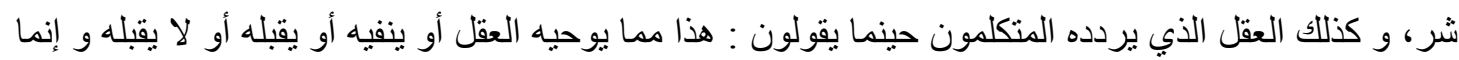
يعنون به المشهور في بادئ الر أي عند الجميع أو الأكثر(V). و يربط الفار ابي السعادة بالمعرفة العقلية، إذ بهذه

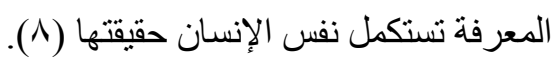

أما ابن سينا فالإدر اك عنده يكون عن طريق الحواس، و الحواس نوعان: ظاهرة وباطنة، و الظاهر خمس هي اللمس و الذوق و الثم والسمع والبصر .... ثم هنالك الحس المشترك، و لا عضو ظاهر لله، و إنما هو نتيجة

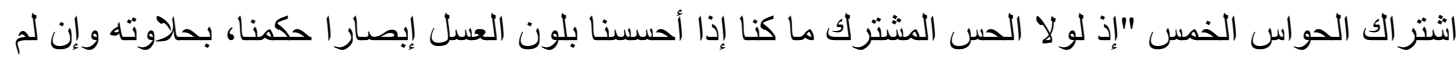

$$
\text { نحس حلاوته"(9). (9) }
$$

و الطريقة الثنانية لاكتساب المعرفة وهي المعرفة النظرية و لا يدركها إلا من وصل إلى مدينة العقل المستفاد

و الطريق الثالث هو الحدس و الإشر اق وهي خاصة بمن منحوا القوة الحدسية أو العقل الحسسي وهم فئة قليلة

من الناس: الأنبياء و الأولياء و المتصوفة الو اصلون (1) (1).

170 1 17 (1)

(Y) محمد عابد الجابري: بنية العقل العربي: دراسة تحليلية نقدية لنظم المعرفة في الثقافة العربية، المركز الثقافي

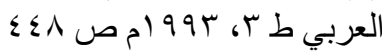
(ץ) محمد العربي بو عزيزي: نظرية المعرفة عند الرازي من خلال تفسيره دار الفكر دمثق سورية يونيو سمو ام ص

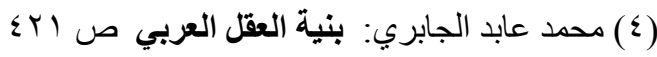

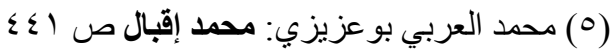

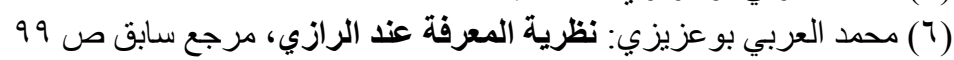

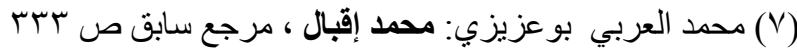

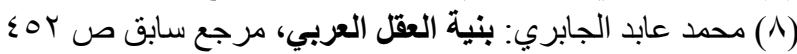

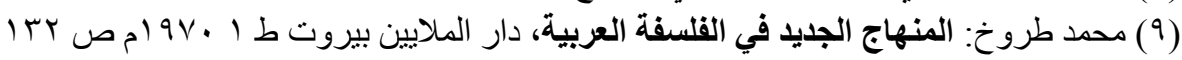

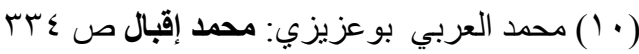

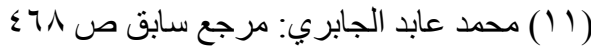




\section{المطلب الثالث: المعرفة عند المتكلمين:}

اهتم علماء الكلام وخصوصا المتأخرون منهم بنظرية المعرفة اهتماما كبير ا فأصبح كل منهم يستهل كتابه بأبو اب يتحدث فيها عن النظر و العلم والطرق المؤدية إليه، فكيف نظر علماء الكلام إلى الطرق الموصلة إلى

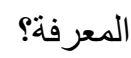

\section{دـ نظرية المعرفة عند المعتزلة:}

تعتمد نظرية المعرفة عند المعتزلة على المعرفة الحسيةو المعرفة النظرية أو العقلية، أما بخصوص المعرفة الحسية فقد حاول المعتزلة تفسير كيفية معرفتنا للعالم في بواسطة الحس، وذهب بعضهم إلى أن النفس تدرك

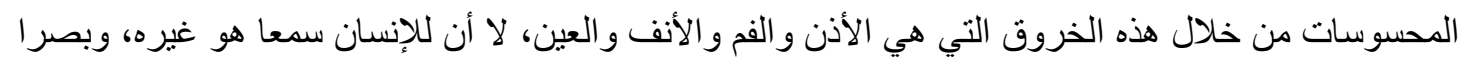

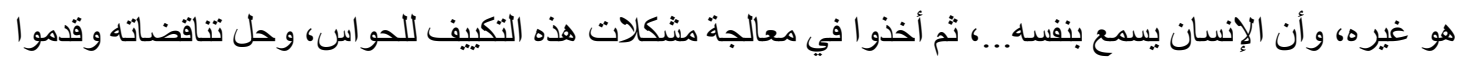
في هذا الإطار آراء طريفة، كتنوع الحواس واختلافها و آفاتها وأغلاطها، وتنوع المحسوسات، وفى أثناء ذلك

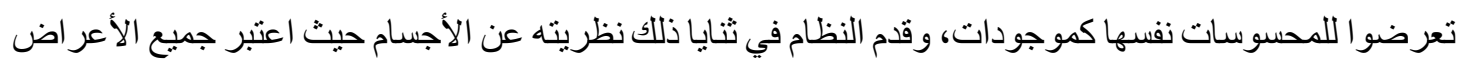

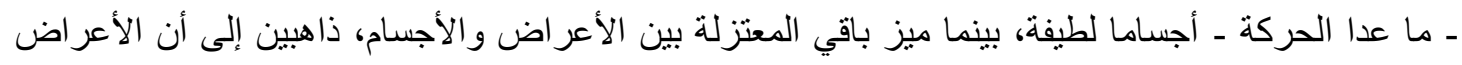
وحدها هي المحسوسة، مقدمين في مشكلة كيف تتحول المحسوسات إلى إحساسات حلو لا متعددة متميزة، وهكذا نرى على سبيل الإجمال أن المعتزلة تعترف بأهمية الحواس في تكوين المعرفة الحسية، والحواس في نظرهم

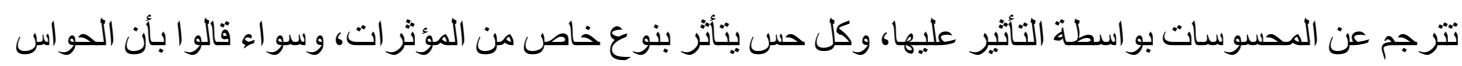

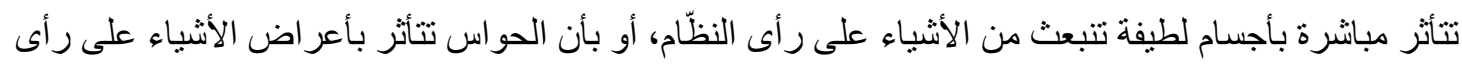

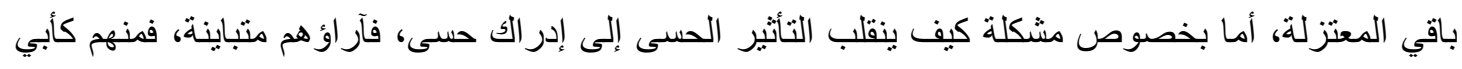
الهذيل من قال إن ذلك يتم بفعل إلهى(')، ومنهم من قال بفكرة التولد، ومنهم من قال بأن العقل يمكنه تحويل

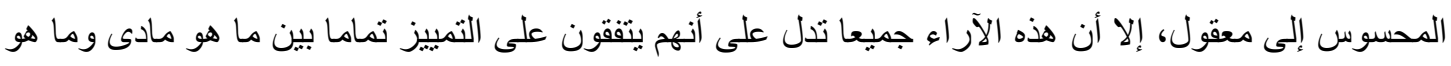

وبجانب المعرفة الحسية تقول المعتزلة بالمعرفة العقلية، وتعتبر العقل قوة في إمكانها أن تدرك الحقائق الفائقة على الحس، كما أنها تدرك الحقائق الأخلاقية الأساسية، و المعرفة الحسية عندهم هي المرحلة الأولى من العلم، وتليها المعرفة العقلية،

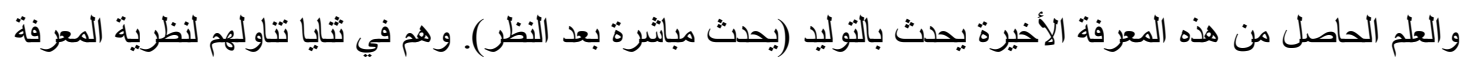
يتعرضون للعليد من المشكلات المعرفية ويحاولون الإجابة عن كثير من الأسئلة مثل: كيف يعمل العقل النظري حتى ينتج هذا العلم؟ وبمقضى أي مبادئ يعمل هذا العقل؟ وهل توجد فيه مبادئ غريزية وبعض الأفكار الكامنة وغير المكنسبة من التجربة؟

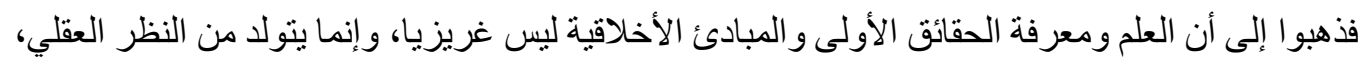

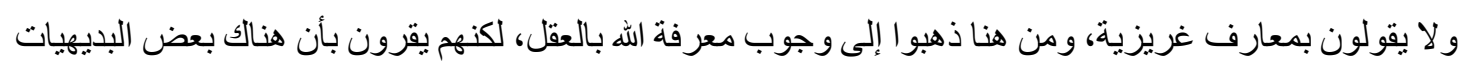
التي يدركها العقل بو اسطة الحسس لا بالاستدلال، وحكم هذه البديهيات عندهم كحكم البديهيات الرياضية، يقبلها العقل و لا يستطيع البرهنة عليها. وبناء على نظرتهم إلى المعرفة العقلية كان موققهم من النقليد والمعرفة النقلية، 
وحيث كان العلم النظري هو اعتقاد الثنيء على ما هو به، فلا مانع عندهم من قبول المعرفة النقلية إذا طابقت الواقع، ومن ثم فلا يؤخذ عذدم بالنقل إلا إذا وافق العقل. وبناء عليه يمكن القول بأن المعتزلة تعتبر العقل هو المقياس الوحيد للحقيقة،

$$
\text { وهو الطريق الوحيد للمعرفة الحقيقية (1)، }
$$

أما بالنسبة للمعرفة النقلية فقد كان للمعتزلة نظرات في شأنها خاصة بهم، فهم يقبلون ما يعلم صدقه اضطر ار ا كالأخبار المتواترة التي يقل عدد من يخبر بها عن خمسة، ويقبلون خبر ما يعلم صدقه استدلالا، و أما ما لا يعلم كونه صدقا ولا كذبا فهو كأخبار الآحاد، وما هذه سبيله يجوز العمل به إذا ورد بشر ائطه، فأما قبوله فيما طريقه الاعتقادات فلا(؟)، على أن ثمة خلاف بينهم في العدد الذى يحصل به التو اتر، ولهذه المسألة نتائج خطيرة فيما يتعلق بنق الأخبار ، ولهذا فهي مسألة منهجية بالغة الأهمية، تناولها المتكلمون في معظم مباحثهم الكلامية(')،

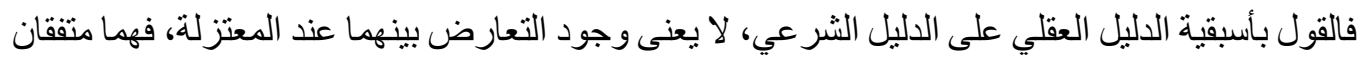
ومتطابقان إذ ليس في القرآن الكريم إلا ما يوافق طريقة العقل، غاية الأمر أنهم حاولوا الاحتكام إلى العقل وحده

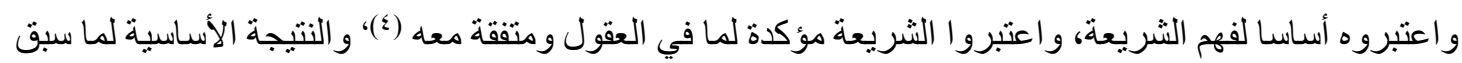
في أثره على مناهج التصنيف هي أبو اب السمعيات عند المعتزلة.

\section{لدـ نظرية المعرفة عند الأثثرية:}

الأشعري والأشاعرة بعامة برون أن النظر في معرفة الله واجب شرعام()، فهذه أول مسألة يبنونها على نظرية المعرفة عندهم، وهم في ذلك يختلفون عن المعتزلة الذين يرون أن معرفة الله تجب بالعقل. وتبنَْى نظرية المعرفة عند الثيخ الأشعري على الجمع بين النقل والعقل، و التحديد الدقيق لمجال كل منهما، فيقول رحمه الله: (وكل ما ذكرناه من الآي أو لم نذكره أصل وحجة لنا في الكلام فيما نذكره من تفصيل، و إن لم تكن مسألة معينة

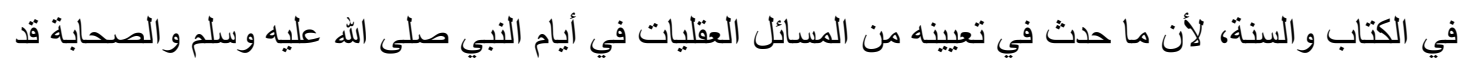

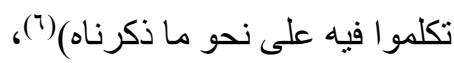
ثم يتابع كلامه (و الجو اب الثالث أن هذه المسائل التي سألوا عنها قد علمها رسول الله صلى الله عليه وسلم ولم يجهل منها شيئا مفصلا، غير أنها لم تحدث في أيامه معينة فيتكلم فيها أو لا يتكلم فيها، و إن كانت أصولها موجودة في القر آن و السنة، وما حدث من شيء فيما له تعلق بالدين من جهة الثريعة فقد تكلمو ا فيه وبحثّ ا عنه، وناظروا فيه، وجادلوا، وحاجو ا... مما قد حدثت في أيامهم ولم يجئ في كل واحدة منها نص عن النبي صلى الله

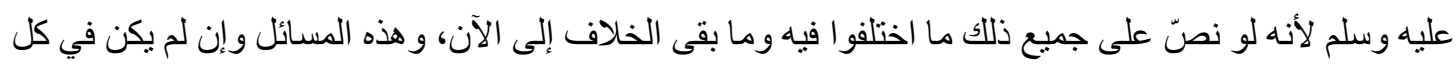
و احدة منها نص عن رسول الله صلى الله عليه وسلم فإنهم ردو ها وقاسو ها على ما فيه نص من كتاب الله تعالى لهي

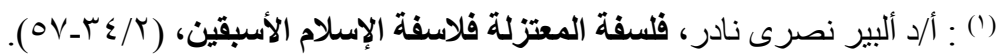

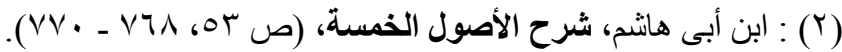

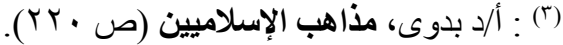
(8) : د/ نصر حامد أبو زيد، الاتجاه العقلي الخارجي التفسير - دراسة الخارجي قضية المجاز الخارجي القرآن عند 
و السنة واجتهادهم، فهذه أحكام حو ادث الفروع ردو ها إلى أحكام الثريعة التي هي فروع لا تستدرك أحكامها إلا من جهة السمع و الرسل، فأما الحوادث التي تحدث في الأصول في تعيين مسائل فينبغي لكل عاقل مسلم أن يرد حكمها إلى جملة الأصول المتفق عليها بالعقل والحس و البديهة و غير ذللك، لأن حكم مسائل الثرع التي طريقها

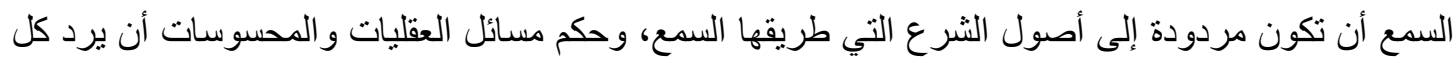
شيء من ذلك إلى بابه، و لا تخلط العقليات بالسمعيات، ولا السمعيات بالعقليات، فلو حدث في أيام النبي صلى الله

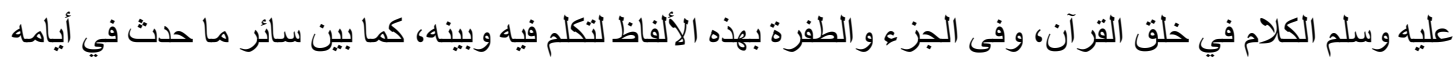

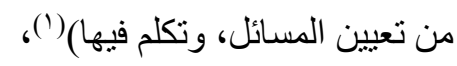
إذن فالنقل و العقل والحس مصادر المعرفة عند الأشعري، و النقل مصدر للمعرفة فيما طريقه السمع من مسائل الثرع، و العقل و الحس مصدر المعرفة فيما هو من مسائل العقليات و الحسيات ((برد كل شيء من ذلك إلى بابه، و لا تخلط العقليات بالسمعيات، ولا السمعيات بالعقليات))، كما في النص السابق. أما عن علاقة النقل بالعقل

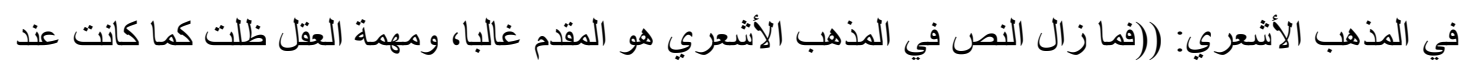

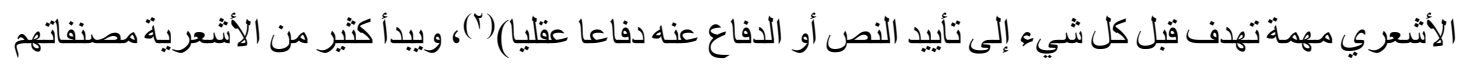
بعرض نظريتهم في المعرفة، فيتكلمون عن العلم وحقيقته، و أقسامه من ضروري وكسبي وقديم ومحدث، وأن

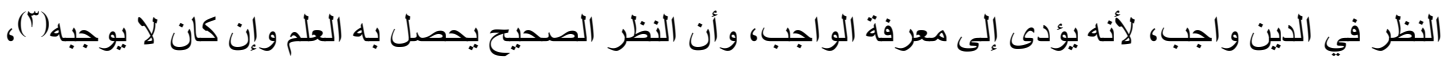

\section{ج- نظرية المعرفة عند الماتريدية:}

يعتبر الماتريدي من أو ائل المتكلمين الذين تكلمو ا على المعرفة بطريقة منظمة، وكان التعرض لها قبل ذلك في شذرات و إنـار ات متفرقة، وأهم الخصائص المميزة لنظرية المعرفة عند الماتريدي(؛)، على ما يلي:

$$
\text { ( ) عدم التفرقة بين العلم و المعرفة. }
$$

Y) نفى الوجود الذهني، فالعقل بيت الحس، ومعنى هذا أن الحواس تنقل المعرفة إلى العقل، وليس في العقل شيء لم يكن قبل ذلك الحس فيه، و العلم عنده علم بالمذكور الجزئي المحسوس.

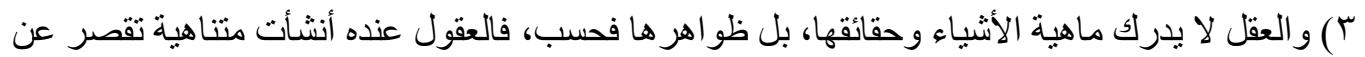
الإحاطة بكلية الأشياء.

ع) ويترتب على ذلك أن التعريفات إنما هي لصفات الأشياء وللتمبيز بينها وبين غير ها. 0) ويقف الماتريدي موقفا منميزا من الظن، حيث يحوله من الجانب السلبي إلى جانب الإيجابي، وير اه دافعا إلى النظر و التأمل فيما خفي حتى نصل إلى اليقين.

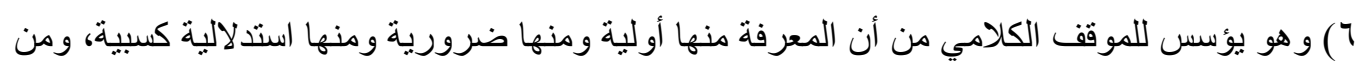
خلال نصوصده يتبين أن الاعتقاد عنده ذاتي بينما المعرفة موضو عية.

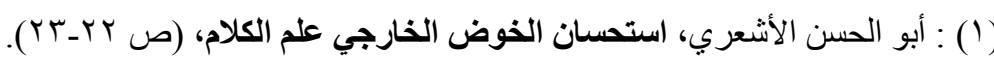

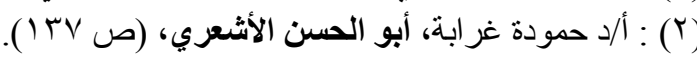

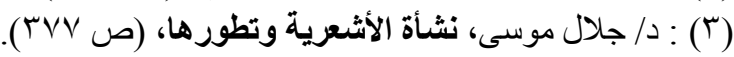

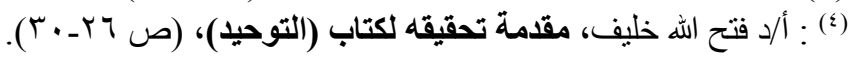


مؤكدا على أن طرق المعرفة هي العيان والأخبار والنظر ، وقد أفاض في بيان حقيقة النظر و أهميته، وأسس ذلك

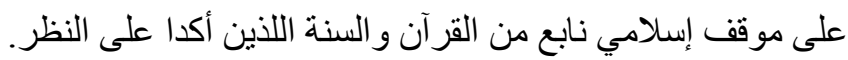
V يؤكد الماتريدي على أن المعرفة الدينية هي أسمى أنواع المعرفة، وسبيل الوصول إليها هو بالاجتهاد. وأن العقل مدرك لضرورة الدين، ولصدق الرسل، ويجب عليه الدفاع عن الدين. ^) أما عن طرق النظر العقلي عند الماتريدي فقد استخدم أغلب أنواع القياس التي شاعت ون بين المتكلمين

كقياس الغائب على الثاهد، وقياس الأولى، وقياس الإحر اج، كما استخدم طريقة الإلز ام، و المنهج الجدلي ('). 9) ولم يهتم الماتريدي بوضع قو اعد المعرفة الصحيحة فحسب، بل نبه على الأسباب التي توقع الإنسان في الإحي

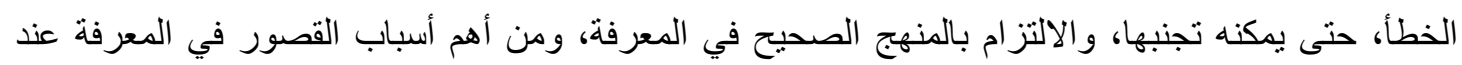

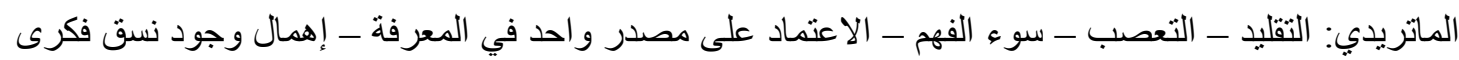
يمنع من تناقضها - عدم إقامة الدليل والاعتماد على سحر البيان - إدخال العقل فيما لا مجال له فيه. أما ابن تومرت فيرى أن " طرق العلم منحصرة في ثلاثة: الحس و العقل و السمع، فالحس على ثلاثة أقسام:

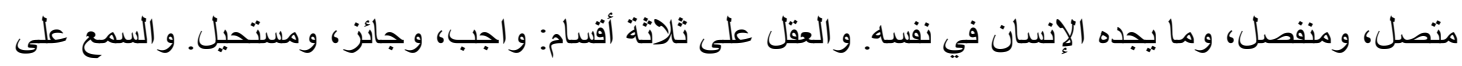
ثلاثة أقسام الكتاب و السنة، والإجماع. هذه آراء بعض فلاسفة المسلمين ومفكريهم عرضتها بمثابة نماذج. فما هي رؤية فلاسفة الغرب المحدثين

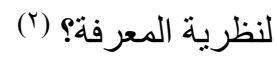

\section{المطلب الرابع: المعرفة عند فلاسفة الغرب المحثثين :}

أما الفلاسفة المحدثون في الغرب فقد انقسموا حول نظرية المعرفة إلى عقليين وتجريبيين و نقديين، و تزعم ديكارت العقليين بل هو المؤسس للعقلانية الحديثة: ويعتقد هؤلاء أن العقل وحده هو منبع جميع الأفكار و هي الفي فطرية فيه و لبست مستمدة من تجربة حسية بل يولد بها الإنسان و قد أو عدها الله فيه (r).

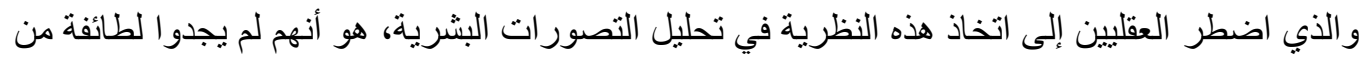

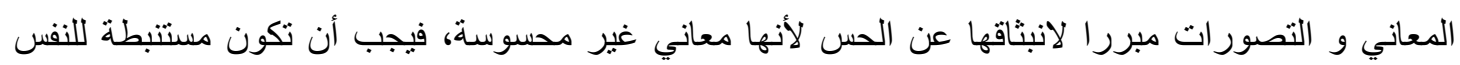
استنباطا ذاتيا من صميمها (๕)

أما التجريبيون فينفون وجود أفكار فطرية في العقل ويعتبرون أن الأفكار مستمدة من التجربة التي ترجع

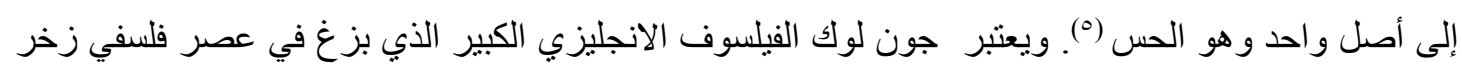
بمفاهيم ديكارت عن الأفكار الفطرية، فبدأ في تفنيد تلك المفاهيم، ووضع لونئ لأجل ذلك در استة مفصلة للمعرفة الإنسانية في كتابه "مقالة في التفكير الإنساني" و حاول إرجاع جميع التصورات و الأفكار إلى الحس و قد شاعت هذه

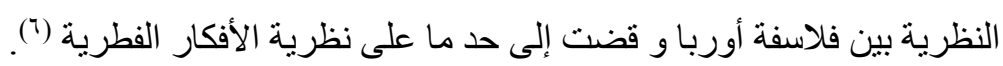

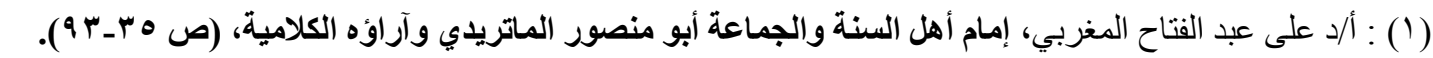

(Y) محمد تومرت: أعز ما يطلب تقديم وتحقيق دكتور عمار الطالبي. المؤسسة الوطنية للكتاب الجز الئر.

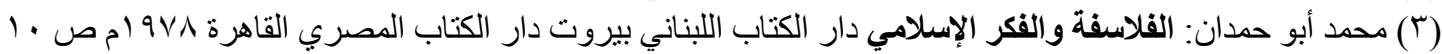

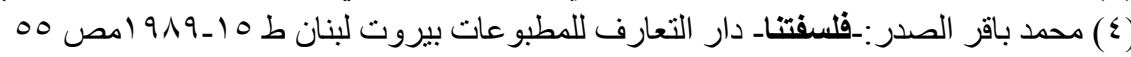

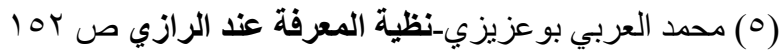

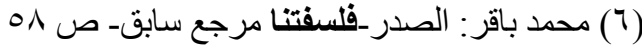


و قد تبنت الماركسية هذه النظرية فقال ماوتسي تونغ موضحا الر أي الماركسي في المسالة " إن مصدر كل

$$
\text { معرفة يكمن في إحساسات أعضاء الحس الجسمية في الإنسان للعالم الموضو عي الذي يحيطه('). }
$$

أما نظرة النقديين بز عامة كانط فهي مخالفة لكلا الاتجاهين السابقين حيث سلكو ا مسلكا وسطا بين العقليين و التجريبيين فحصروا الحقيقة المعرفية في عالم الظواهر وحده و رأوا ضرورة الجمع بين التجربة و العقل كمصدرين للمعرفة " فالعلم بالأثياء مرجعه إلى التجربة، و لكن الإدر اك الحسي لا يستقيم بغير مبادئ أولية بديهية

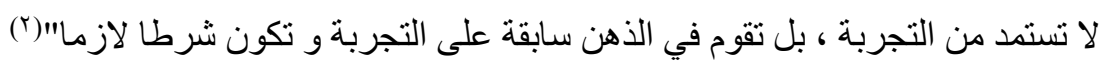
و بهذا يكون النقديون قد جمعو ا بين التجريبيين و العقليين معا فالمعرفة عندهم "ترد إلى عامل صوري هو

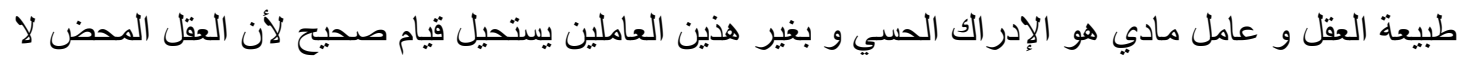
يزود الإنسان بحقائق لها قيمة علمية"(ّ) حسب هذا الاتجاه الفلسفي الذي يوحد بين المصدرين معا "و يرى أن أن المعرفة تكمن في الخبرة الحسية و المبادئ العقلية معا إذ كل جزء من معارفنا يقوم في مضمونه على الحواس و

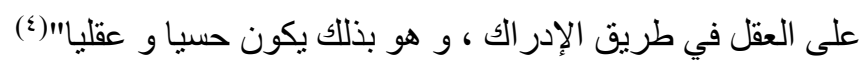
هذه لمحة موجزة عن مبحث المعرفة و كيف تعاطى معه المفكرون من فلاسفة يو نانيين و مسلمين و متكلمين و فلاسفة غربيين محدثين. فكيف نظر إليها محمد إقبال ؟ هل جاء إقبال بقيمة مضافة إلى نظرية المعرفة خاصة

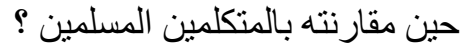

\section{المطلب الخامس: المعرفة عند إقبال:}

أثار مبحث المعرفة اهتمام إقبال وذللك راجع إلى السياق التاريخي الذي فرض عليه تناول هذا المبحث،

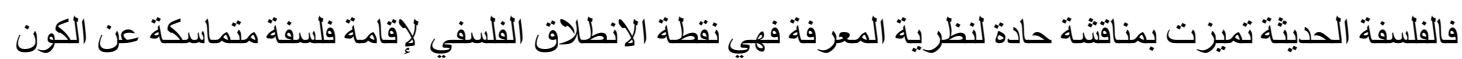
و ون العالم (0). فعندما جاء المتكلم في العصر الحديث لإثبات وجود الله مثلا رأى أنه لم يعد يقف أمام ملاحدة القرون الغابرة بل وجد إلحادا بررته قضية المعرفة و لو لا قضية المعرفة التي سادت منذ القرن السادس عشر لما لهاء

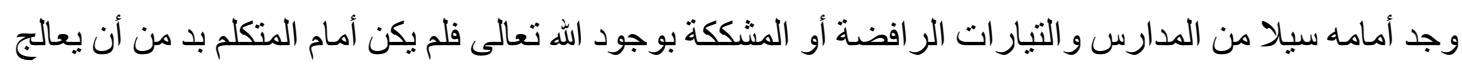

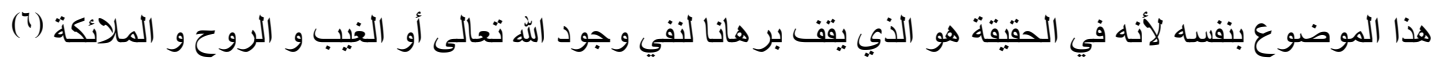
فكانت هذه بعض المبررات التي جعلت إقبال يتناول هذا المبحث بالدرس و التحليل ضمن محاضر اته

$$
\text { الفلسفية (Y) كما عرج عليه في ثنايا مؤلفاته الثعرية. }
$$

فهو يخصص أولى تللك المحاضر ات التي جاءت تحت عنوان "المعرفة والرياضة الدينية" للحديث عن مشكلة المعرفة من حيث طبيعتهاو وسائلهاو الغاية منها ، و يمهد لذلك بطرحه أسئلة أنتلوجية من قبيل ما طبيعة العالم الذي نعيش فيه و ما بناؤه العام ؟ أهناك عنصر ثنابت في نركيب الكون ؟ و كيف نكون بالنسبة إليه؟

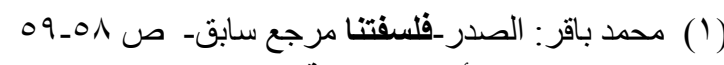

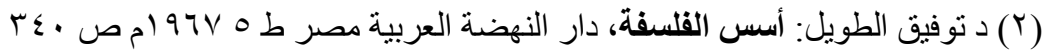

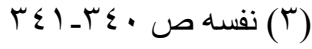

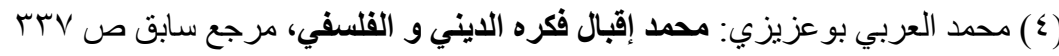

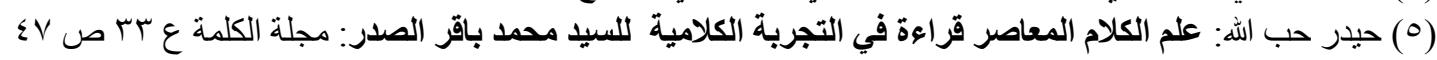


و أي مكان نشغله منه و ما نوع السلوك الذي يتفق و هذا المكان الذي نشغله؟. و حين يشرع في الإجابة عن تساؤ لاته يرى أن طبيعة هذه لتساؤلات مشتركة بين الدين و الفلسفة و الشعر العالمي الرفيع و يذهب إلى أن المعرفة التي ولي نحصل عليها عن طريق الإلهام الثعري شخصية بالضرورة في نوعهاو في طبيعتها و هي رمزية المضمون ، بخلاف الدين ، فهو يسمو فوق الثعر و يتخطى الفرد إلى الجماعة ليجابه حقائق الكون النهائية و يزودنا بصورة

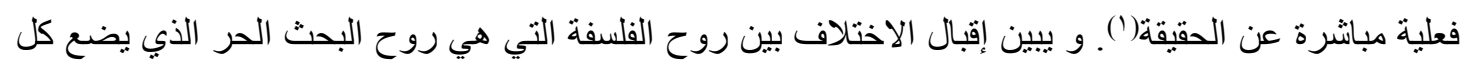

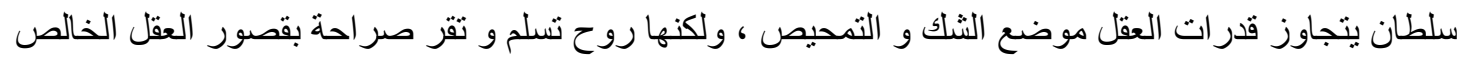

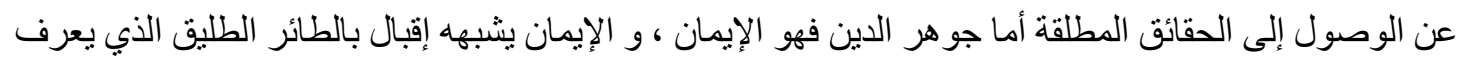
طريقه الخالي من المعالم غير مسترشد بالعقل(؟). ولما كان الهدف الأساسي هداية النفس البشرية باطنيا و خارجيا فمن الطبيعي ألا تبقى حقائق غبر مبر هن عنها، ولكن لا يستلزم التسليم بسمو الفلسفة على الدين ، و أنه لبس من الصحة في شأن بان الفكر و البداهة متضسادان

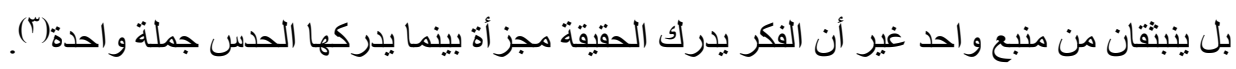
بعد إجابته عن الأسئلة الوجودية التي طرحها إقبال يعرف المعرفة بقوله "هي الإدر الك الحسي الذي يكمله لهانه الإدر الك العقلي"() و يستدل على ذلك بقوله تعالى (و إذ قال ربك إني جاعل في الأرض خليفة قالو ا أتجعل فيها

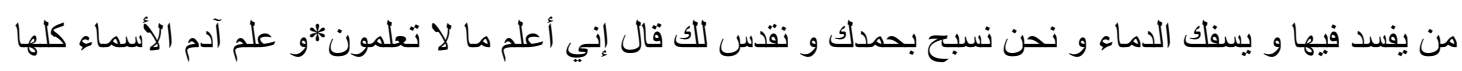

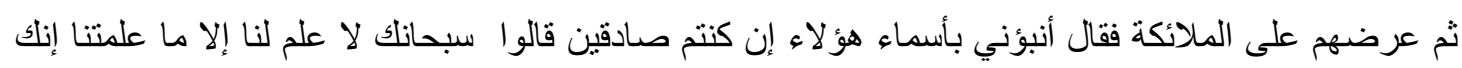

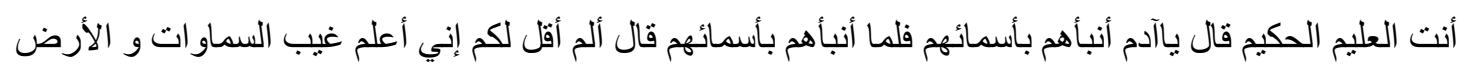

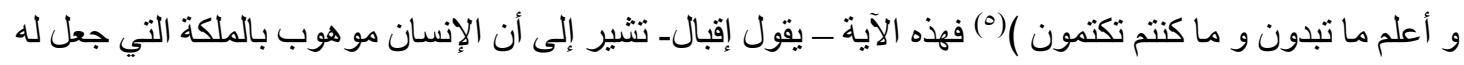

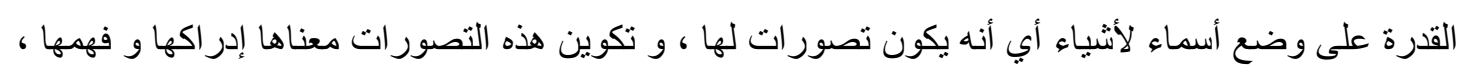

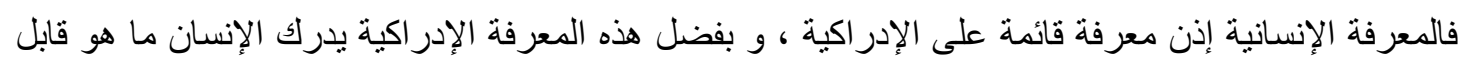

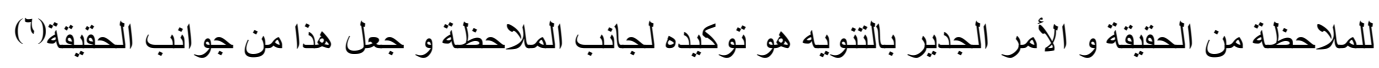

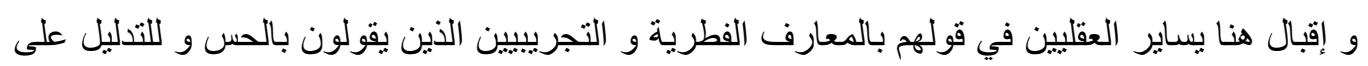

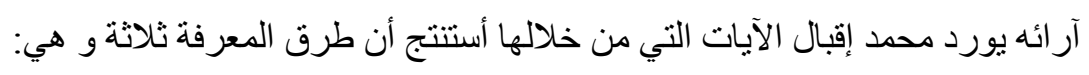

الإدراك الحسي:

حيث اعتبره مصدر ا هاما في عمليات الإدر الك المعرفية على غرار من سبقه من فلاسفة الإغريق و الإسلام و التجريبيين حديثا(Y). و هذا ما جعله في غير ما مرة يشير في ثنايا محاضر اته إلى تأكيد القرآن الكريم على دور الحواس و الملاحظة الحسية في سبيل الوصول إلى الحقيقة المعرفية.

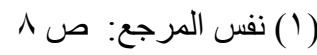

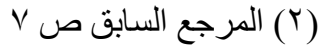

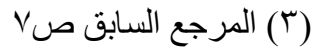

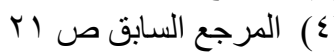

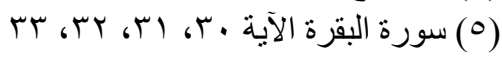

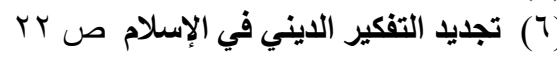

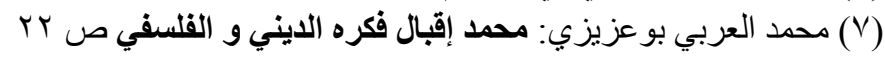


״ فأول ما يستهدفه القرآن من هذه الملاحظة التأملية للطبيعة هو أنها تبعث في نفس الإنسان شعورا بمن جعل

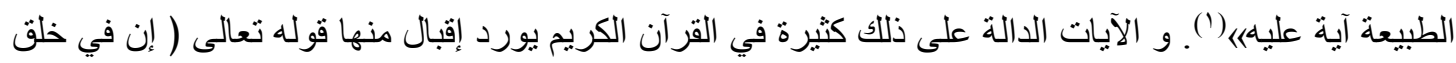

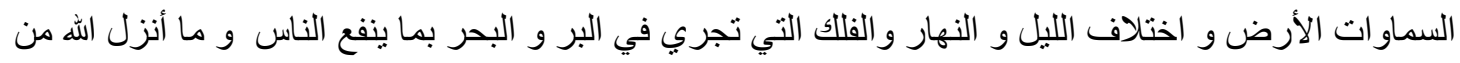
السماء من ماء فأحيا به الأرض بعد موتهاو بث فيها من كل دابة و تصريف الرياح و السحاب المسخر بين السماء

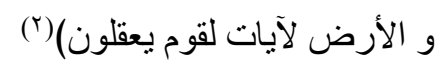

و قوله تعالى(هو الذي جعل لكم النجوم لتهندوا بها في ظلمات البر و البحر قد فصلنا الآيات لقوم يعلمون

و قوله تعالى (ألم تر إلى ربك كيف مد الظل و لو شاء لجعله ساكنا ثم جعلنا الثمس عليه دليلا ، ثم قبضناه

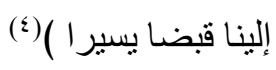

و قوله تعالى (أفلا ينظرون إلى الإبل كيف خلقت و إلى السماء كيف رفعت و إلى الجبال كيف نصبت و

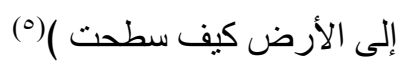

و قوله تعالى (و من آياته أن خلق السماوات و الأرض و اختلاف ألسنتكم و ألو انكم إن في ذلك لآيات

(7)( للعالمين)

و ينوه إقبال بتميز التوجه القرآني عن غيره من المناهج المعرفية قائلا: "و إنه لأمر عظيم حقا أن يوقظ

القرآن نلك الروح التجريبية في عصر كان برفض عالم المرئيات بوصفه فليل الفناء في بحث الإنسان ور اء الخالق

و يرد محمد إقبال على فلاسفة اليونان من خلال انتقاده لسقر اط فيقول "و كان سقر اط يقصر همه على عالم

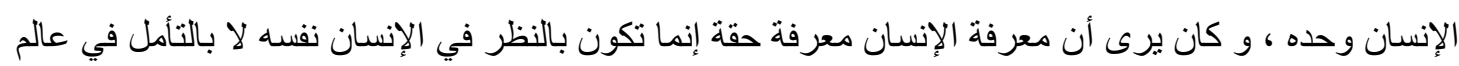

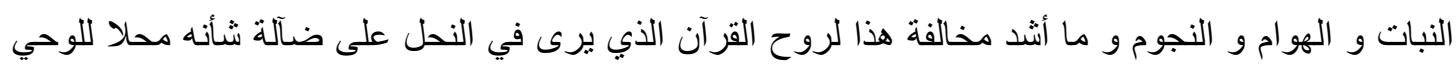

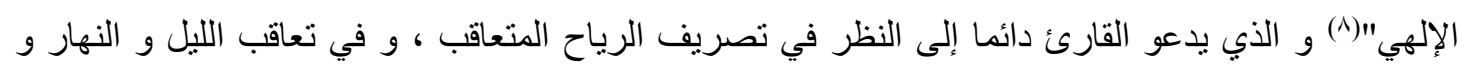

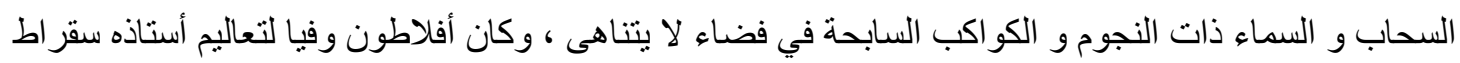

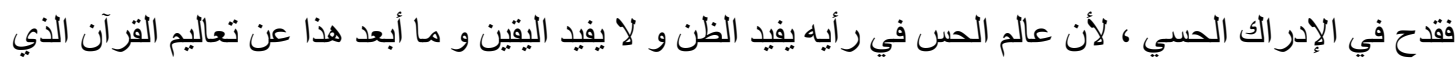

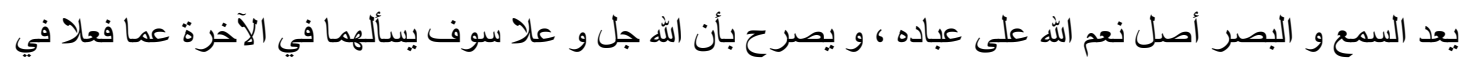

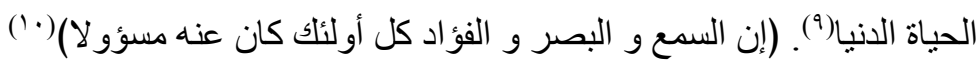

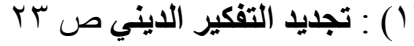

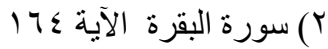

$$
\begin{aligned}
& 9 \text { 9 سورة الأنعام الآية }
\end{aligned}
$$

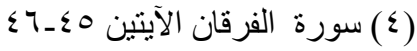

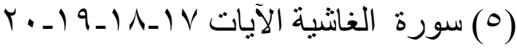

$$
\begin{aligned}
& \text { (†) سورة الروم الآية بr الايت }
\end{aligned}
$$

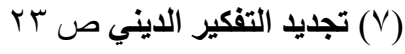

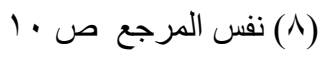

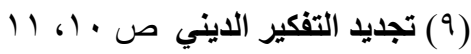

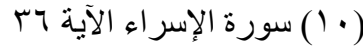


و يؤكد إقبال في موطن آخر على دور الحس في الحصول على المعرفة عند حديثه عن نأثير النقافة الإسلامية في الثقافة الأوربية و الكثف عن اعتماد هذه الأخيرة في بداية قيامها على العلوم الإسلامية و خاصة مناهجها التجريبية و الاستقر ائية(') فيقول: و أول نقطة هامة نلاحظها في روح الثقافة الإسلامية هي أنها في سبيل

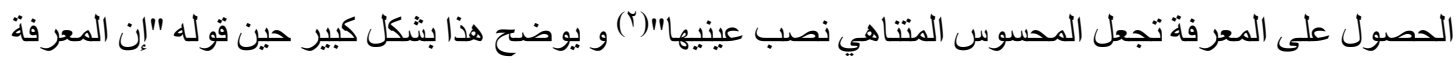
يجب أن تبدأ بالمحسوس و قدرة العقل على تحصيل المحسوس و سلطانه عليه هو الذي ييسر له الانتقال من المحسوس إلى غير المحسوس"("). و هكذا يتضح كيف آمن إقبال بوجود الحس و اعنبره وسيلة معرفية جد هامة و أكد على دعوة القرآن الكريم إلى اعتمد الحواس للتأمل في الموجودات الطبيعية آية دالة على وجوده و عظمته"(؛)

\section{الإدراك العقلى}

إلى جانب الحس يشكل العقل مصدرا رئيسيا و هاما للمعرفة عند محمد إقبال فهو يثبت العقل و يقر به وسيلة معرفية لا غنى عنها على غر ار من سبقه من الفلاسفة قدامى و محدثين.

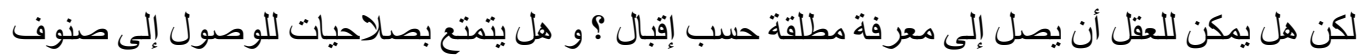

إن المنصفح لكتابه تجديد الفكر الديني يجد أن إقبال يتردد و يتأرجح بين المذهب العقلي و بين المذهب

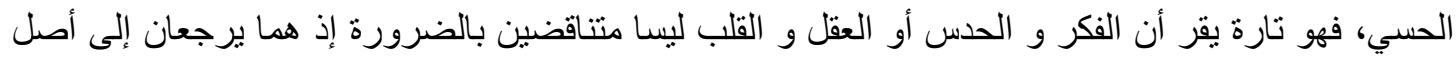

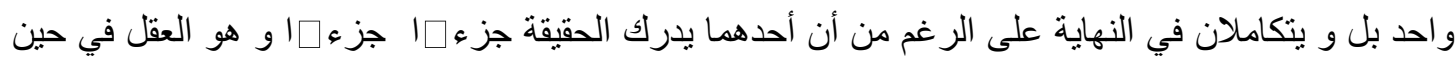
يدركها الآخر جملة واحدة و هو الحدس و أن كلا منهما يفتقر إلى الآخر (०). و يؤكد إقبال أن البداهة و هي الحدس ليست إلا ضربا من التفكير العالي كما يذهب إلى ذللك برجسون"(ج). و نارة أخرى يذهب إلى أن العقل ير عى إدر الك الحقيقة الكليةو ذللك راجع إلى مواجهته للجزئيات المتناثرة

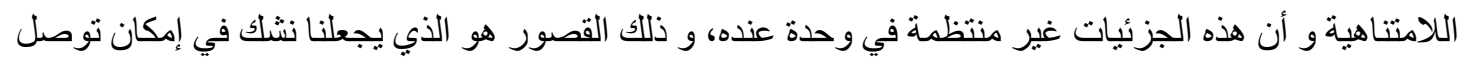
العقل إلى إدر اك كامل و نهائي للحقيقة لأن طريقته قائمة على التعميمات، و هي ليست إلا وحدات وهيل وهية لا تؤثر 
ثم يأتي إقبال ليبين أن من الخطأ أن نحسب الفكر غير قادر على الوصول إلى أحكام قاطعة فإنه هو أيضا على طريقته الخاصة (') و و "الر أي القائل بأن العقل في جوهره متناه، ومن ثم لا يقدر على إدر الك غير المتناهي، رأي ينهض على تصور خاطئ لحركة العقل في تحصيل المعرفة "(؟) ويمكن تبرير ما يذهب إليه إقبال في قضية تحصيل المعرفة بالعقل (التي فيها شيء من التردد) إلى قوله

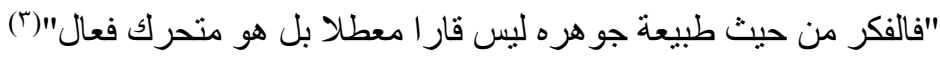
كما أن إقبال على الر غم من إيمانه العميق بفعالية الإدر اك العقلي في تحصيل المعرفة فإنه لا يريد أن يرجح

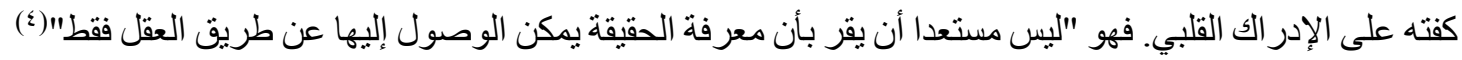
و هو هنا يو افق المتصوفة الذين لا يثقون بالعقل كثثر ا، فالعقل عندهم ضعيف عاجز ، لا يجرؤ على الإقدام على

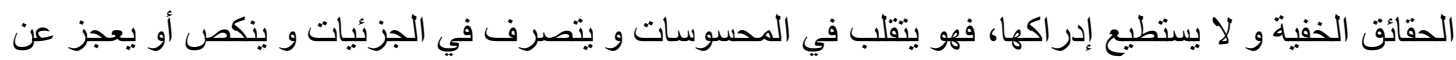

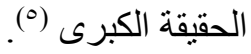

\section{الإدراك القلبى (الحدس)}

يذهب إقبال إلى أن القلب يعد وسيلة معرفية هامة في عالم الرياضة الباطنية للوصول إلى كثف الحقيقة

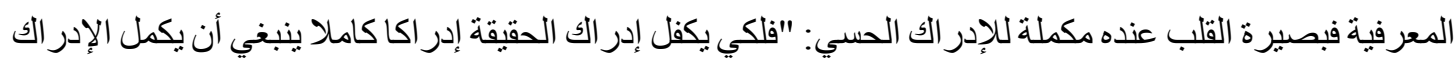
الحسي بإدر الك آخر هو ما يصفه القرآن بإدر الك الفؤاد أو القلب"(ج). و يستشهد بقو له تعالى (الذي أحسن كل شيء خلقه و بدأ خلق الإنسان من طين؟ ثم جعل نسله من سلالة من

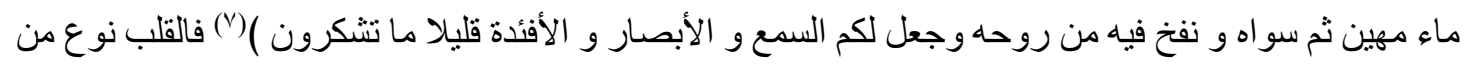
علم الباطن أو البداهة (^) ، و يصفه الثناعر جلال الدين الرومي في عبارة طيبة فيقول : إنه يتغذى بأنشعة الثمس ونس

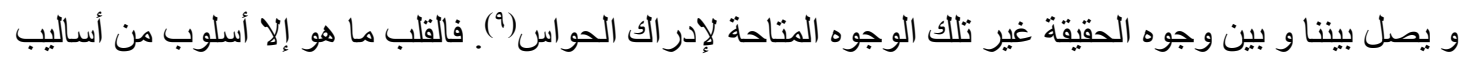

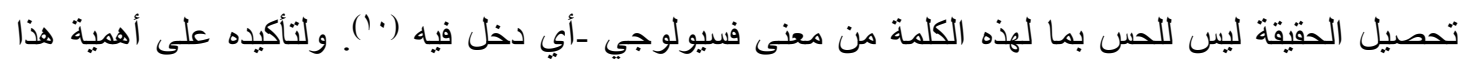
المصدر _الحسـ- المعرفي، يقدمه إقبال على العقل فهو يعتبر العقل ظن وتخمين في قوله:

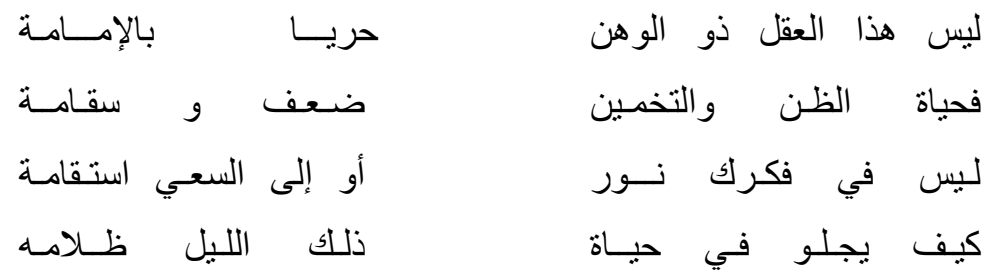


لبعي ذا الفهامـة (1) إن لغز الحسن والقبح

وفي مقارنتهما ـالقلب و العقل-يقول إقبال:

و طوى الأفـلاك و الأرض مسير ا سيطر العقل على الكون أميرا

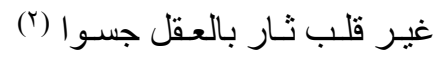

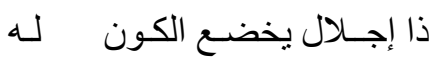
ويقول كذلك:

$$
\begin{aligned}
& \text { في الغرب العقل مصدر للحيـاة } \\
& \text { وفي الثـرق: الحب قو ام الحيـاة } \\
& \text { وبو اسطة الحب يحيط العقل بالحقائق }
\end{aligned}
$$

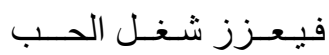

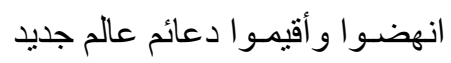

$$
\begin{aligned}
& \text { بالتوفيـق بين العقل و الحب (َ) }
\end{aligned}
$$

و هكذا يتضح لنا أن مصادر المعرفة عند إقبال هي الحس و العقل و الحدس و الله عز و جل يقول: (و لقد ذر أنا لجهنم كثثر ا من الجن و الإنس لهم أعين لا يبصرون بها و لهم آذان لا يسمعون بها )(ؤ) في هذه الآية يلفت

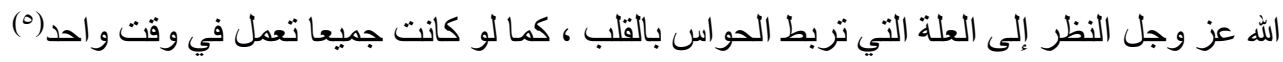
و إن كان إقبال يقدم الحدس على المصدرين السابقين الآخرين الحس و العقل و هو بذللك يو افق المتصوفة في نظرتهم لنظرية المعرفة. فالقتشيري مثلا يقول: "و الناس إما أصحاب النقل والأثر و إما أرباب العقل و الفكر و شيوخ هذه الطائفةـ الصوفية_ارتقوا عن هذه الجملة فالذي للناس غيب فهو لهم ظهور، و الذي للخلق من المعارف مقصود فلهم من

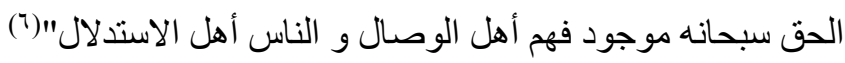

$$
\begin{aligned}
& \text { (1) محمد إقبال: ضرب الكليم: ترجمة الدكتور عبد الوهاب عزام - دار المعارف مصر } 1907 \text { مص ع }
\end{aligned}
$$

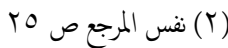

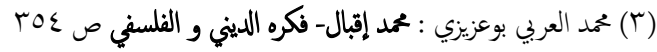

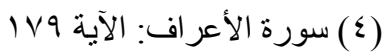

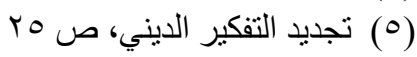

$$
\begin{aligned}
& \text { (7) عبد الكريم هوزان القنشيري: الرسالة دار الكتاب بيروت(دت) ص |N| }
\end{aligned}
$$




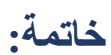

و هكذا تكتمل الرؤية المعرفية لإقبال التي تتماثى فيها والوجهة القرآنية التي تقوم على الحواس و العقل و القلب و هي بذلك وجهة و اقعية تعتمد على الحس و العقل و البصيرة وتعترف بدور كل مصدر في تحصيل المعرفة. و هي بذلك تخالف الاتجاهات الفلسفية المختلفة التي تعد أحادية الجانب، فهي إما تنادي بالحس فقط أو بالقلب وحده و هذا ما يجعل إقبال يتميز في رؤيته المعرفية.

\section{بعض نتائج البحث}

إن إعادة طرح قضية نظرية المعرفة في العصر الحديث يرجع أساسا إلى التحديات المعرفية التي واجهها العقل المسلم في تلك المرحلة

إن البحث المقارن في نظرية المعرفة بين رؤيتين فلسفيتين يفيد في فهم التباين الحاصل بين الددارس

$$
\text { الفلسفية }
$$

ل إن رؤية محمد إقبال تتميز بكونها تجمع بين العقل و القلب.

\section{توصيات البحث}

ل ضرورة إعادة قر اعة تراث الفيلسوف محمد إقبال

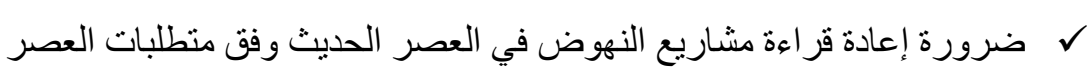

ل لابد من أعادة تفكيك سؤال النهضة الذي طرحه الأمير شكيب أرسلان وفق حاجة العصر و أدو اته

$$
\text { ومناهجه المعرفية }
$$

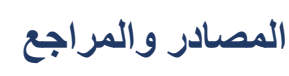

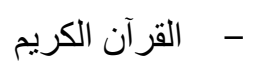

ألبير نصرى نادر ، فلسفة المعتزلة فلاسفة الإسلام الأسبقين، مطبعة دار نشر الثقافة،، طا، ـ190

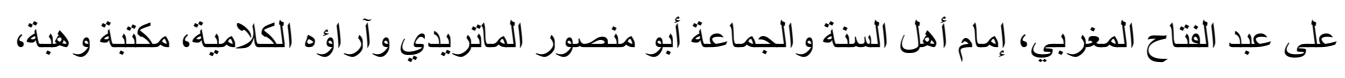

$$
\text { مصر، ط1)، 1910 190 }
$$

الماتريدي، كتاب التوحيد، المحقق: د. فتح الله خليف النانر : دار الجامعات المصرية ـ الإسكندرية، طا،

$.19 \vee$.

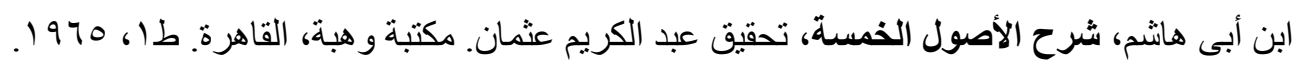
أبو الحسن الأشعري، استحسان الخوض الخارجي علم الكلام، دار المشاريع للطباعة و النشر والتوزيع، طله اله

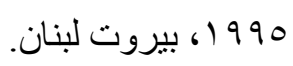

الكندي: الرسائل الفلسفية: تحقيق محمد عبد الهادي أبو ريدة: دار الفكر العربي مطبعة الاعتماد مر •و90 ام

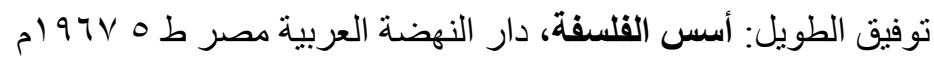


جلال موسى، نشأة الأشعرية وتطور ها، دار الكتاب اللبناني للطباعة و النشر و التوزيع، ب 191.

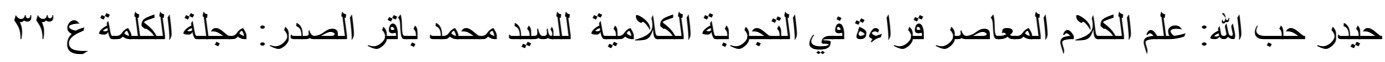

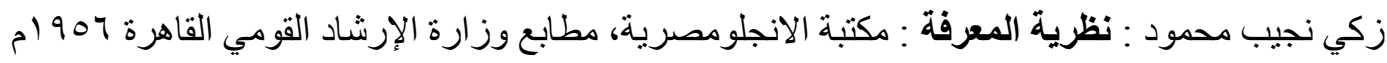

عبد الرحمان بدوى، مذاهب الإسلاميين، دار العلم للملايين. طا، لو9 19. عبد الرحمن بدوي: طريق الفكر اليوناني : مكتبة النهضة المصرية القاهرة ط ع . • 19Vم

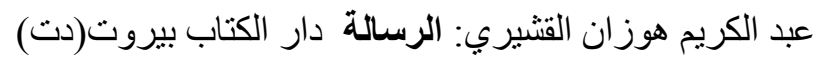
عثمان أمين: دراسات فلسفية مهداة إلى الدكتور إبراهيم مذكور: الهيئة المصرية العامة للكتاب: القاهرة م $19 \vee \varepsilon$

عز ام :التصوف و فريد الدين العطار- دار إحياء الكتب العربية مصر 0ـ 9 ام

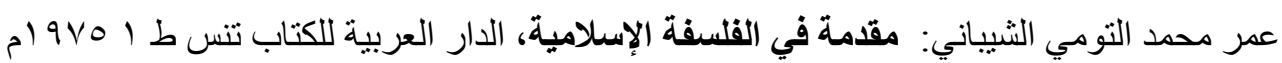
عيدة الثمالي : دراسات في تاريخ الفلسفة العربية الإسلامية و آثار رجالها دار بيروت لبنان ط ع 970 ام محمد أبو حمدان: الفلاسفة والفكر الإسلامي دار الكتاب اللبناني بيروت دار الكتاب المصري القاهرة 9V^ام

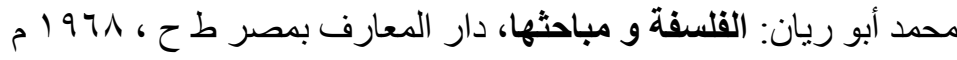
محمد إقبال: تجديد التفكير الديني في الإسلام، ترجمة عباس محمود، مطبعة لجنة التأليف و الترجمة و النشر:

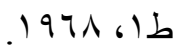
محمد إقبال: ضرب الكليم: ترجمة الدكتور عبد الوهاب عز ام - دار المعارف مصر 907 ام م 1907 م محمد العربي بوعزيزي : محمد إقبال- فكره الديني و القلسفي، دار الفكر المعاصر ، دمشق، 1999 محمد العربي بو عزيزي: نظرية المعرفة عند الرازي من خلال تفسيره دار الفكر دمثق سورية يونيو بهـو ام

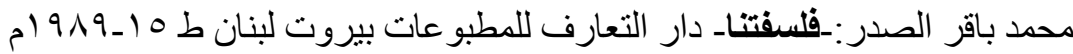
محمد تومرت: أعز ما يطلب تقديم وتحقيق دكتور عمار الطالبي. المؤسسة الوطنية للكتاب الجزائر. 1910 ـ

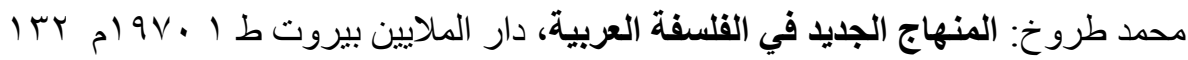
محدد عابد الجابري: بنية العقل العربي: دراسة تحليلية نقدية لنظم المعرفة في الثقافة العربية، المركز

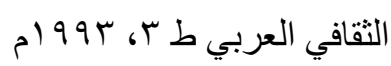

محمد علال: المعرفة عند مفكري المسلمين، الدار المصرية للتأليف و النشر ، القاهرة 974 ام 97 نصر حامد أبو زيد، الاتجاه العقلي الخارجي التفسير - دراسة الخارجي قضية المجاز الخارجي القرآن عند

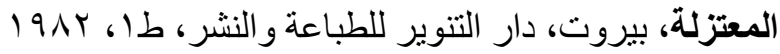

جميع الحقوق محفوظة 2020 C) د: عبد الله الزكي، المجلة الأكاديمية للأبحاث و النشر العلمي. (CC BY NC) 